Check for updates

Cite this: RSC Adv., 2018, 8, 19041

\title{
Decontamination of radioactive cesium ions using ordered mesoporous monetite
}

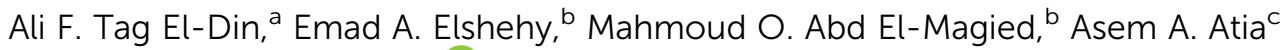 \\ and Mohamed E. El-Khouly (D)*a
}

We report herein the fabrication of an environmentally friendly, low-cost and efficient nanostructured mesoporous monetite plate-like mineral $\left(\mathrm{CaHPO}_{4}\right)$ as an adsorbent for removal of radioactive cesium ions from aqueous solutions. The phase and textural features of the synthesized mesoporous monetite were well characterized by XRD, FTIR, SEM, HRTEM, DLS, TGA/TDA, and $\mathrm{N}_{2}$ adsorption/desorption techniques. The results indicate that the cesium ions were effectively adsorbed by the mesoporous monetite ion-exchanger (MMT-IEX) above pH 9.0. Different kinetic and isotherm models were applied to characterize the cesium adsorption process. The fabricated monetite exhibited a monolayer adsorption capacity up to $60.33 \mathrm{mg} \mathrm{g}^{-1}$ at $\mathrm{pH}$ of 9.5 . The collected data revealed the higher ability of $\mathrm{CaHPO}_{4}$ for the removal of $\mathrm{Cs}(\mathrm{I})$ from aqueous media in an efficient way.

Received 28th March 2018

Accepted 16th May 2018

DOI: $10.1039 / \mathrm{c} 8 \mathrm{ra0} 2707 \mathrm{~b}$

rsc.li/rsc-advances

illite, montmorillonite, kaolinite, ${ }^{11}$ nano-zeolite, ${ }^{12}$ zinc hex-

\section{Introduction}

Cesium (Cs) is an alkali metal with one naturally occurring isotope $\left({ }^{133} \mathrm{Cs}\right)$ which is ubiquitous in the environment with concentrations in the Earth's crust ranging between 0.3 and 25 parts per million. As is well known, cesium isotopes are produced as byproducts of nuclear fission processes in nuclear reactors, nuclear weapons tests, and some nuclear accidents. These nuclear evolutions have resulted in high release of Cs isotopes into the aquatic environment. Among them, ${ }^{134} \mathrm{Cs}$, ${ }^{135} \mathrm{Cs}$, and ${ }^{137} \mathrm{Cs}$ are of particular danger due to their high environmental mobility. ${ }^{\mathbf{1 - 5}}$ The transport of radionuclides through aquatic systems is partially dependent on the physical and chemical properties of the nuclide and the water body. ${ }^{\mathbf{1 - 3}}$ From a chemical point of view, Cs is a chemical analog to potassium, being a monovalent cation it would also tend to sorb to most negatively charged surfaces.

In the last decade, there has been considerable interest in sequestering of cesium ions from the aquatic environment. The applied technologies for the separation of cesium include: solvent extraction, ${ }^{6}$ precipitation, ${ }^{4}$ ion exchange, ${ }^{5}$ membranes, ${ }^{7}$ and adsorption. ${ }^{8-10}$ Among them, the ion exchange method has attracted much interest in recent years due to its rapid separation, high thermal and radiation stabilities of the adsorbents, and reduced amount of waste.

Various inorganic adsorbent materials and insoluble salts have been extensively utilized in cesium removal including

${ }^{a}$ Department of Chemistry, Faculty of Science, Kafrelsheikh University, Kafr El-Sheikh 33516, Egypt.E-mail: mohamedelkhouly@yahoo.com

${ }^{b}$ Nuclear Materials Authority, P. O. Box 530, El Maadi, Cairo, Egypt

${ }^{c}$ Department of Chemistry, Faculty of Science, Menoufia University, Menoufia, Egypt acyanoferrate, ${ }^{\mathbf{1 3 , 1 4}}$ copper ferrocyanide, ${ }^{\mathbf{1 5}}$ ammonium molybdo-

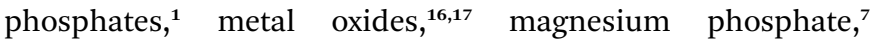
tungstates, ${ }^{18}$ titanium and zirconium phosphate. ${ }^{19}$ Recently, calcium phosphate $(\mathrm{CaP})$ materials, with different calcium-tophosphate molar ratios, have attracted much attention for removing the radioactive species from contaminated media. Calcium based materials for removal of radioactive species has been focused on hydroxyapatite (HAP) and tri-calcium phosphate (TCP). Compared with them, dicalcium phosphate cements such as monetite $\left(\mathrm{CaHPO}_{4}\right)$ are non-toxic and low cost. These advantages render it as promising materials in various applications such as: drug delivery, orthopedics, cancer therapy, biosensors, biological matrixes, and water treatment. $^{20-23}$

The aim of the present study is to design simple and cost effective technique for the synthesis of ordered nanostructured mesoporous calcium hydrogen phosphate (i.e. monetite (MMTIEX)) sorbent by a sol-gel method for cesium ion removal in an efficient way. The textural and structural characteristics of MMT-IEX were examined using different analytical and spectroscopic techniques. The effect of $\mathrm{pH}$, eq. time, and cesium ion concentrations on the adsorption removal efficiency were clarified. The obtained adsorption data was applied to different isotherm models, kinetics and thermodynamic studies.

\section{Materials and methods}

\subsection{Materials}

Cesium nitrate solution (1000 mg $\mathrm{L}^{-1}$ in $0.05 \mathrm{M} \mathrm{HNO}_{3}$ ) was purchased from Merck Company. Calcium nitrate tetrahydrate $\left(\mathrm{Ca}\left(\mathrm{NO}_{3}\right)_{2} \cdot 4 \mathrm{H}_{2} \mathrm{O}\right)$, ammonium hydroxide $\left(\mathrm{NH}_{4} \mathrm{OH}\right)$, cellulose 
acetate, ammonium dihydrogen phosphate $\left(\mathrm{NH}_{4} \mathrm{H}_{2} \mathrm{PO}_{4}\right)$, phosphoric acid $\left(\mathrm{H}_{3} \mathrm{PO}_{4}\right)$, ethanol and dodecylamine hydrochloride were ADWIC products, Egypt. The solution was further diluted to the required concentrations $\left(1-150 \mathrm{mg} \mathrm{\textrm {L } ^ { - 1 }}\right)$ with deionized water. The solution's $\mathrm{pH}$ was adjusted by $0.01 \mathrm{M}$ nitric acid or $0.01 \mathrm{M}$ sodium hydroxide solutions.

\subsection{Fabrication of ordered nanostructured mesoporous monetite}

Monetite meso-sorbent was synthesized using the conventional sol-gel method through three consecutive steps. Firstly, calcium nitrate $(6.5 \mathrm{~g})$ was dissolved in $9 \mathrm{~mL}$ ammonia solution and then $0.9 \mathrm{~g}$ dodecylamine hydrochloride was added to the solution with stirring. $2.3 \mathrm{~g}$ of $\mathrm{NH}_{4} \mathrm{H}_{2} \mathrm{PO}_{4}$ was dissolved in $10 \mathrm{~mL} \mathrm{H}_{2} \mathrm{O}$ and then added to the former solution. Secondly, a $0.6 \mathrm{~g}$ cellulose acetate dissolved in water/ethanol solution (1:1) was subsequently added vigorous stirring to the former solution. The mixture was stirred for $3 \mathrm{~h}\left(\right.$ at $\left.70{ }^{\circ} \mathrm{C} ; \mathrm{pH}=7.8\right)$ after which $5 \mathrm{~mL} \mathrm{H}_{3} \mathrm{PO}_{4}(85 \%)$ was added dropwise with stirring. The reaction was performed at $70{ }^{\circ} \mathrm{C}$ for $6 \mathrm{~h}$ stirring until the gelatinous white precipitate (monetite-CA) was obtained. The gelatinous precipitate was kept with mother liquor for $24 \mathrm{~h}$ at room temperature and then the resulting adsorbent was filtrated and washed several times to remove remaining agents. Finally, the asmade MT-CA-DA was dried at $75^{\circ} \mathrm{C}$ for $8 \mathrm{~h}$ and carefully heated in air by heating rate $25{ }^{\circ} \mathrm{C} \mathrm{min}^{-1}$ from room temperature to $500{ }^{\circ} \mathrm{C}$ for 3 hours. The obtained material (MMT-IEX) was characterized and further used for the cesium ions removal process.

\subsection{Materials characterization}

Surface functional groups of the fabricated monetite were identified using Fourier transform infrared spectrometer (FTIR, 640-MSA, Thermo Electronics Co). The phase and mineral composition of the fabricated TM-MS was investigated by X-ray diffraction spectroscopy with a Philips X-ray generator model PW $3710=31$. Thermo-gravimetric analysis (TGA) was carried out in a nitrogen atmosphere using Shimadzu DT $=$ TG-50 with a heating rate of $10{ }^{\circ} \mathrm{C} \mathrm{min}^{-1}$. The particle size distribution and zeta potential were measured using a Nano Series Zeta Sizer (Malvern; Worcestershire, UK). The particle size distribution and hydrodynamic diameter of the fabricated MMT-IEX were evaluated through dynamic light scattering (DLS). The sample (0.5 $\mathrm{mg} \mathrm{mL}^{-1}$ ) was suspended in DIW and ultrasoundirradiated for $5 \mathrm{~min}$. The cesium and conjugated ions concentrations were analyzed using inductively coupled plasma-optical emission spectrometer (ICP-OES, 720-ICP-OES, Agilent Technologies).

Pore-size distribution and Brunauer-Emmett-Teller (BET) specific surface area were calculated using the nitrogen adsorption/desorption method at $77 \mathrm{~K}$ (using a BELSORP MINII analyzer, JP. BEL Co. Ltd). Morphological characteristics of the adsorbent were examined using high-resolution fieldemission scanning electron microscopy (ESEM) EXL 130 attached by energy dispersive spectrometry (EDX) unit system. High-resolution transmission electron microscopy (HRTEM), scanning electron microscopy (SEM), and elemental mapping of
MMT-IEX product were performed using an energy-filtered TEM (EFTEM). The HRTEM, STEM, and STEM-EDS were operated at a camera length of 20 and a spot size of $1 \mathrm{~nm}$. STEM and STEMEDS were carried out at a camera length of $40 \mathrm{~cm}$ and a spot size of $0.7 \mathrm{~nm}$. For characterization, the MMT-IEX was dispersed in ethanol solution using an ultrasonic cleaner and then dropped on a copper grid.

\subsection{Batch studies for Cs(I) ions adsorption on MMT-IEX}

During the adsorption process, the different parameters affected the characteristics of removal Cs(I) ions from aqueous solutions in terms of $\mathrm{pH}$, time, concentration and metal ion diffusion were studied. In a typical Cs(I) ions-adsorption experiments, the MMT-IEX (30 mg) were immersed in a $20 \mathrm{~mL}$ of $\mathrm{Cs}(\mathrm{I})$ ions solution ( $150 \mathrm{mg} \mathrm{L}^{-1}$ ) and adjusted to the desired pH (1-11). The solutions contain MMT-IEX were shaken at $300 \mathrm{rpm}$ for $90 \mathrm{~min}$. After the batch contacts, the adsorbent was separated by filtration through a $25 \mathrm{~mm}$ Whatman filter paper and the remaining Cs ions concentration was determined by ICP-OES. The uptake of cesium ions $q_{\mathrm{e}}\left(\mathrm{mg} \mathrm{g}^{-1}\right)$ is conducted according to eqn (1): ${ }^{7}$

$$
q_{\mathrm{e}}=\left(C_{\mathrm{i}}-C_{\mathrm{e}}\right) V / m
$$

where $q_{\mathrm{e}}$ is the amount of Cs(I) ions (mg) absorbed per one gram of MMT-IEX, $V$ is the solution volume (L), $m$ is the mass of the MMT-IEX $(\mathrm{g}), C_{\mathrm{i}}$ and $C_{\mathrm{e}}$ are the initial and equilibrium concentrations of the cesium ion $\left(\mathrm{mg} \mathrm{L}^{-1}\right)$, respectively. After determining the $\mathrm{pH}$ values of the MMT-IEX, other experiments studies were conducted according to the specific $\mathrm{pH}$ value. In adsorption isotherm experiments, MMT-IEX (30 mg) was immersed in a $20 \mathrm{~mL}$ of different cesium ions concentrations at specific $\mathrm{pH}$ values with stirring for $90 \mathrm{~min}$ at room temperature.

\section{Results and discussions}

\subsection{Characterization of the fabricated monetite}

The monetite, $\mathrm{CaHPO}_{4}$, crystallizes in a triclinic unit cell $a=$ $6.9160 \AA, b=6.9160 \AA, c=6.9460 \AA, a=96.81, b=103.82^{\circ}$, and $c=88.34^{\circ}$ with $Z=4$. Its structure consists of $\mathrm{CaHPO}_{4}$ chains bonded together by $\mathrm{Ca}-\mathrm{O}$ bonds and three types of hydrogen bonds. ${ }^{20-25}$ Two distinct sets of pairs of $\mathrm{PO}_{4}$ units are found in each primitive cell with the $P 1$ space group centered on a symmetric hydrogen bond and the other proton disordered over two centrosymmetrically related positions. ${ }^{24,25}$ The monetite $\left(\mathrm{CaHPO}_{4}\right)$ was prepared by calcination of as-synthesized MT$\mathrm{CA} / \mathrm{DA}$ at $500{ }^{\circ} \mathrm{C}$ for $3 \mathrm{~h}$ due to template elimination (cellulose acetate and dodecylamine). Fig. 1a shows the XRD patterns of the mesoporous crystalline monetite structure. ${ }^{20-24}$ Further, the $\mathrm{X}$-ray diffraction pattern exhibited two intense peaks at $2 \theta$ of $26.5^{\circ}$ and $30.26^{\circ}$ correspond to the calcium hydrogen phosphate. FTIR spectrum of MMT-IEX showed sharp three bands at 1152, 1089 and $950 \mathrm{~cm}^{-1}$ that attributed to $\mathrm{P}-\mathrm{O}$ stretching vibration of $\mathrm{PO}_{4}{ }^{24,25}$ The bands at 950 and $719 \mathrm{~cm}^{-1}$ are associated with asymmetric and symmetric stretching of $\mathrm{P}-\mathrm{O}-\mathrm{P}$ bonds, respectively. The intense bands at 2916, 2360, 1417 and $891 \mathrm{~cm}^{-1}$ are due to $\mathrm{P}-\mathrm{O}(\mathrm{H})$ stretching and bending modes of 

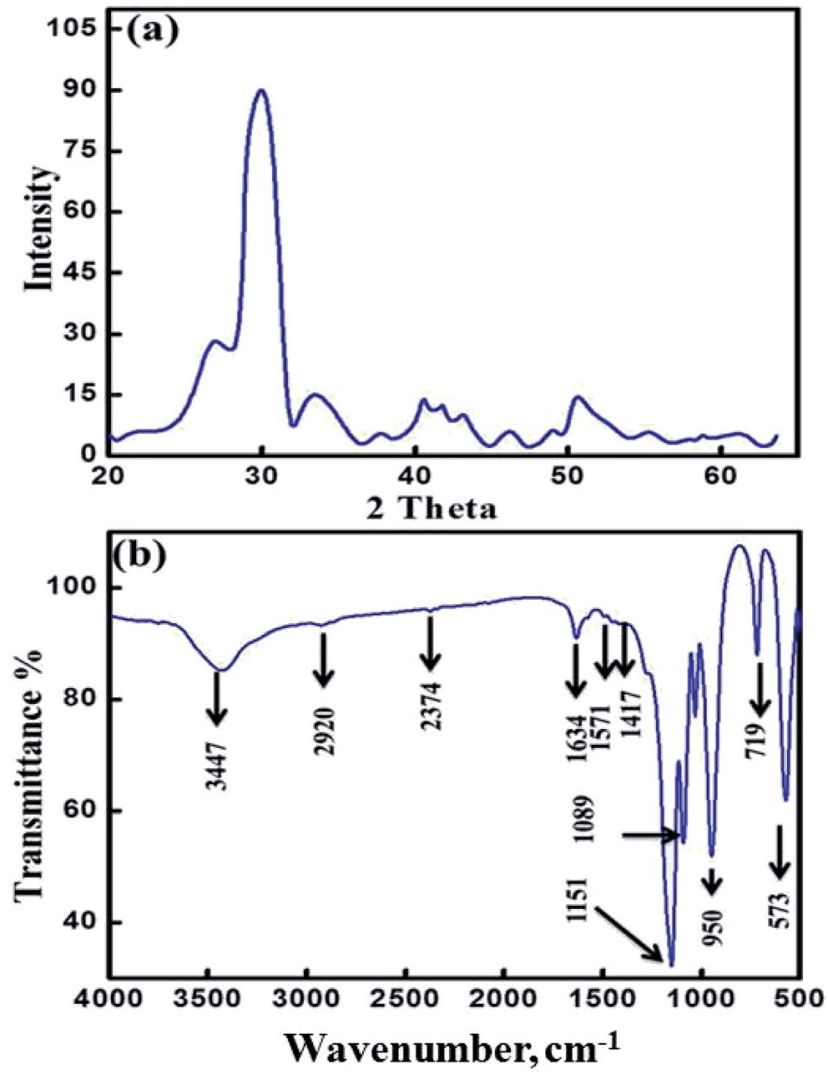

Fig. 1 (a) X-ray diffraction pattern for monetite $\left(\mathrm{CaHPO}_{4}\right)$ sample used in this study; Bragg reflections showed correspond to monetite as detailed in ICDD card number 04-012-8346. (b) FTIR spectra of the mesoporous monetite (MTT-IEX) sample nanoparticles.

the monetite structure. The observed stretching $\nu(\mathrm{OH})$ bands at different IR spectrum seem to be dependent on the three types of hydrogen bonds. Moreover, the absorption band at $573 \mathrm{~cm}^{-1}$ refers to stretching vibration of the $\mathrm{O}-\mathrm{P}-\mathrm{O}(\mathrm{H})$ bond. No $\mathrm{OH}-$ specific bands were found at 1571 and $631 \mathrm{~cm}^{-1}$, indicating that no hydroxyapatite appeared in the finally hardened products and the material is calcium hydrogen phosphate anhydrous. $^{25}$

The $\mathrm{N}_{2}$ isotherm shows a typical type IV adsorption behavior, with a well-known sharp adsorption/desorption inflection and the hysteresis loops shift to higher relative pressure $\left(P / P_{0}\right)$, implying an increase of the pore diameter and the formation mesoporous sorbent. Moreover, the isothermal shape and capillary evaporation indicate the formation of uniformly sized ordered mesopores with pore openings, surface area and pore volume of $31.68 \mathrm{~nm}, 47.0 \mathrm{~m}^{2} \mathrm{~g}^{-1}$ and $0.0333 \mathrm{~cm}^{3} \mathrm{~g}^{-1}$, respectively. Our results show that the assisted cellulose acetate/ dodecylamine hydrochloride can be used to fabricate uniformly mesopores of MMT-IEX. TGA curves display weight losses of $4 \%$ for the calcined MMT-IEX in the temperature range 455-470 ${ }^{\circ} \mathrm{C}$. These weight losses correspond to physisorbed water (Fig. 2b). The DTA curve of MMT-IEX shows two wellpronounced peaks, one endothermic peak in the temperature around $370{ }^{\circ} \mathrm{C}$. This endothermic peak is due to desorption of water and $\mathrm{CO}_{2}$. The exothermic peak indicates that the
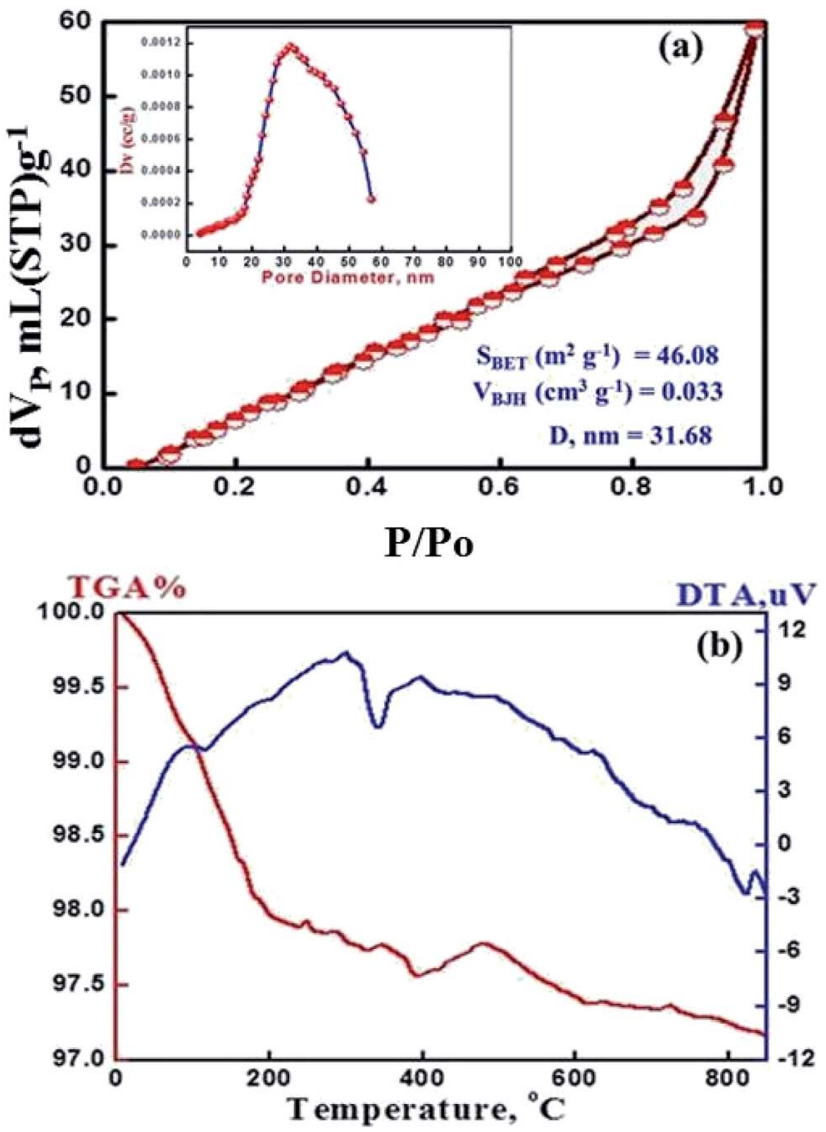

Fig. 2 (a) $\mathrm{N}_{2}$ adsorption-desorption isotherm and pore size distribution plot (inset). (b) TGA/DTA of the mesoporous MMT-IEX nanoparticles.

reformation of the crystalline phase of monetite occurs in temperature at $986^{\circ} \mathrm{C}$.

SEM and TEM images of MMT-IEX sorbent (Fig. 3a-c) show the typical morphology expected for monetite with a rectangular, plate-like crystals. The HRTEM image clearly shows the existence of a crystalline structure and confirming that the sample has an ordered mesoporous structure (Fig. 3d). STEM mappings combined with energy dispersive X-ray spectroscopy (STEM-EDS) analysis were performed to characterize the composition and atomic distribution of fabricated MMT-IEX nanospheres (Fig. 3e). STEM-EDS mapping of the MMT-IEX indicated the presence of O (29.81\%), $\mathrm{P}(37.31 \%)$ and $\mathrm{Ca}(32.88 \%)$ in the composition domains of the monetite mesostructure (Fig. 3e). The dynamic light scattering (DLS) analysis of the monetite exhibits a uniform size in the range of $50-90 \mathrm{~nm}$ in diameter, suggesting the formation of monetite nanoparticles (Fig. 3f).

\subsection{Adsorption assays of cesium ions on MMT-IEX}

3.2.1. Effect of $\mathbf{p H}$. $\mathrm{pH}$ factor plays an important role in controlling the sorption process of the cesium ions. Moreover, it affects both the electrical charge on the surface of the MMT-IEX and the speciation of cesium ions in the solutions. Furthermore, zeta potential depends not only on the particle's surface properties but also the nature of the solution (e.g. ionic 

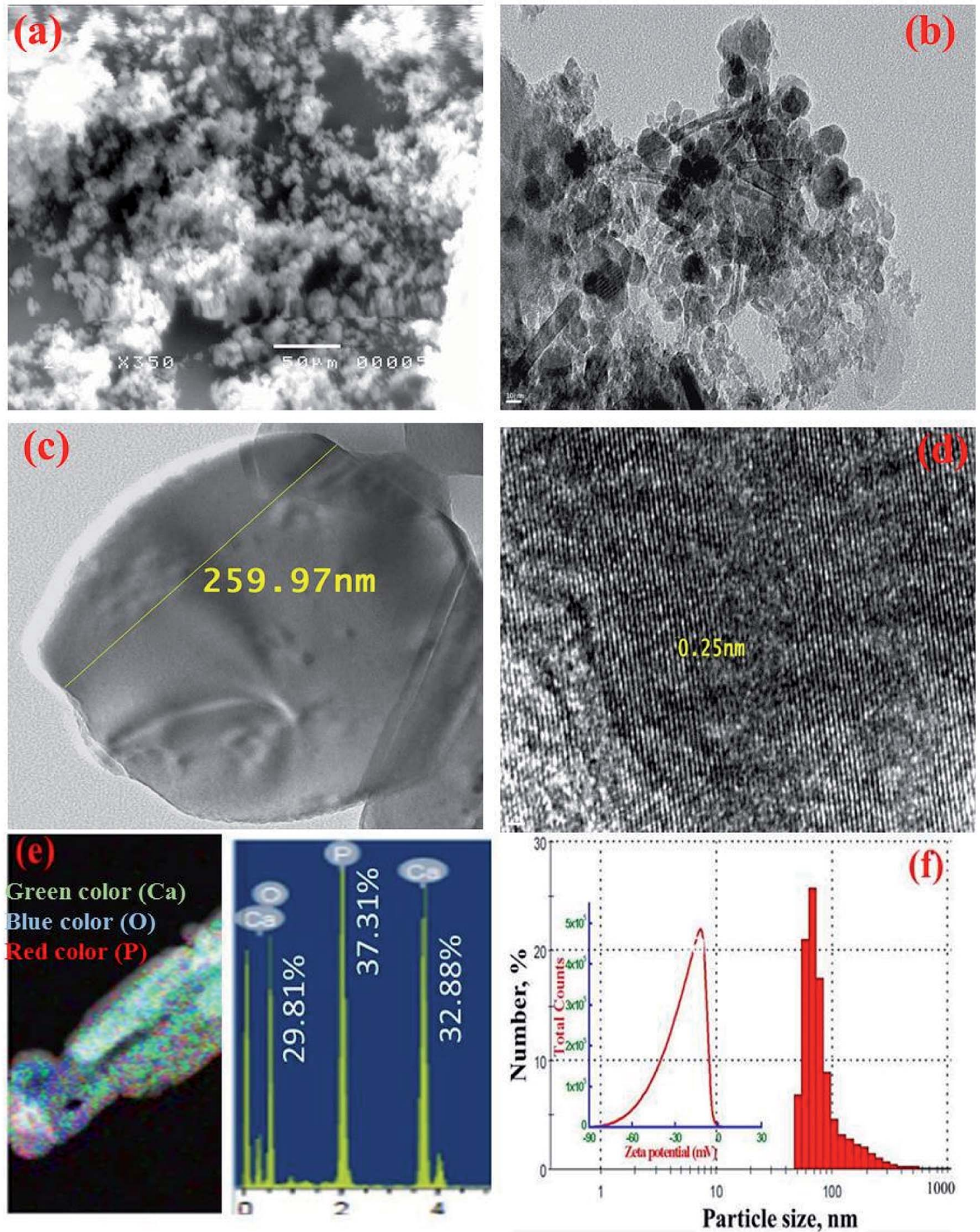

Fig. 3 (a) Representative SEM, (b and c) TEM image for monetite nano-plates with different magnifications, (d) HRTEM shows evidence of the formation of ordered mesoporous structures, (e) STEM images of calcium (green), oxygen (blue) and phosphorous (red) and EDS analysis results, and the calculated values of the atomic abundance of the species present, and (f) particle size distribution and zeta potential (inset) of mesoporous MMT-IEX sorbent.

strength, $\mathrm{pH}$, etc.). The surface zeta potential of MMT-IEX was determined to be $-22.1 \mathrm{mV}$ (Fig. 3f). The negative value is due to the deprotonated $-\mathrm{OH}$ group of the phosphate moiety that can explain the $\mathrm{pH}$ variations of uptake of cesium ions from solution by MMT-IEX. The effect of initial $\mathrm{pH}$ solution on the uptake of Cs(I) ions by MMT-IEX was evaluated over the $\mathrm{pH}$ ranges from 1.0 to 11.0 as shown in Fig. 4a. In ion exchange adsorbent (eqn (2)), Cs(I) uptake at acidic $\mathrm{pH}$ values was suppressed due to the excessive hydronium ions $\left(\mathrm{H}_{3} \mathrm{O}^{+}\right)$near the surface could produce a repulsive force to hinder the approach of the $\operatorname{Cs}(\mathrm{I})$ ions to the sorbent surface. ${ }^{7}$ 

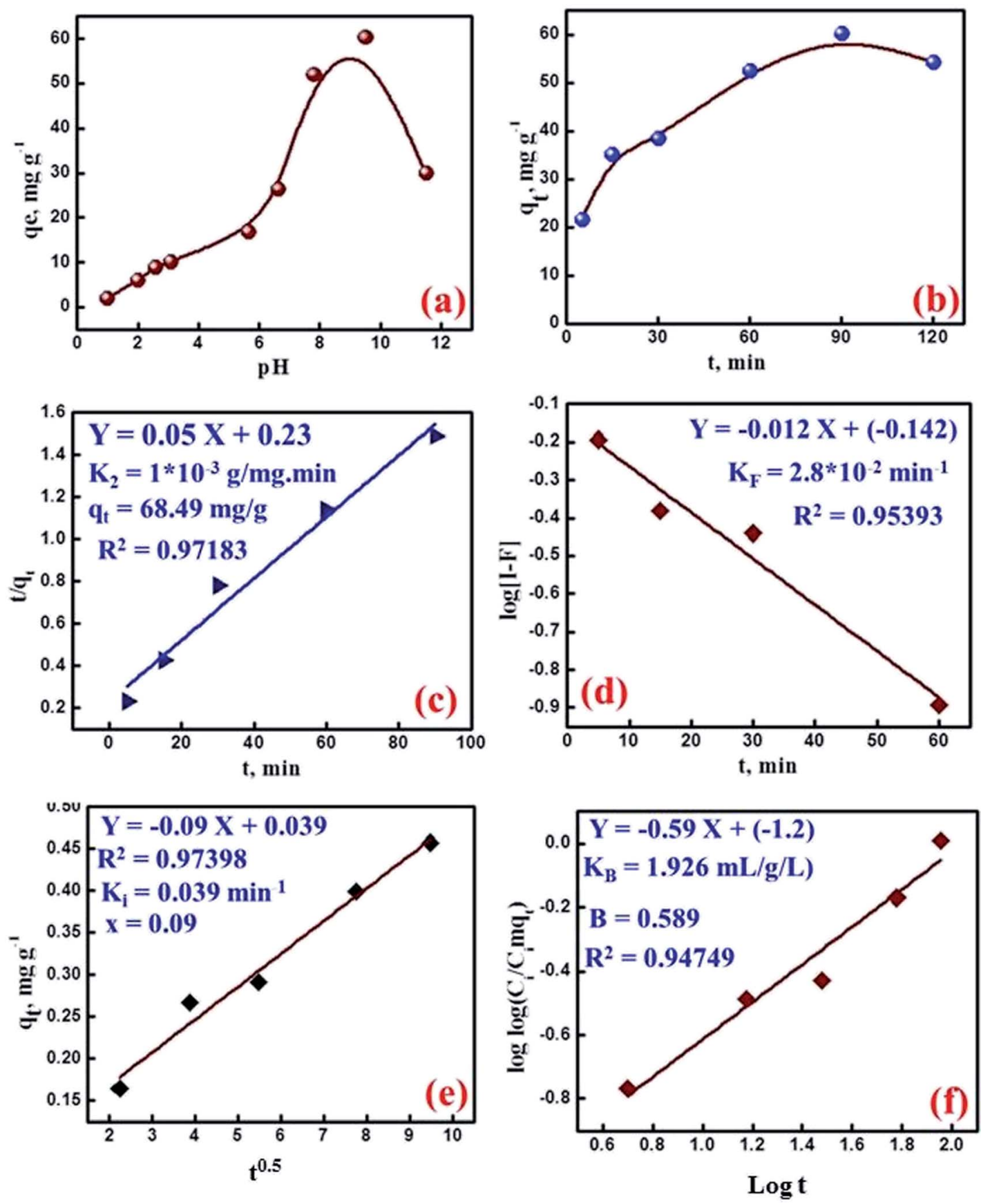

Fig. 4 (a) Effect of $\mathrm{pH}$ on the adsorption of $\mathrm{Cs}\left(\right.$ () ions on CaP-MS; initial Cs(I) concentration $150 \mathrm{mg} \mathrm{L}^{-1}$, MMT-IEX weight 30 mg, solution volume $20 \mathrm{~mL}$, contact time $90 \mathrm{~min}$ and $25^{\circ} \mathrm{C}$. (b) Effect of contact time on the adsorption of Cs(I) ions on MMT-IEX from a single ion solution; pH 9.5 initial Cs(I) concentration $150 \mathrm{mg} \mathrm{L}{ }^{-1}$, MMT-IEX weight $30 \mathrm{mg}$, solution volume $20 \mathrm{~mL}$ at $25^{\circ} \mathrm{C}$. Kinetic profile of the cesium adsorption on MMTIEX with different models. (c) The pseudo-second-order, (d) Weber-Morris, (e) McKay, and (f) Bangham plots for the adsorption cesium on MMTIEX sorbent.

$$
\text { MMT-IEX-OH }+\mathrm{Cs}^{+} \rightarrow \text { MMT-IEX-OCs }+\mathrm{H}^{+}
$$

At higher $\mathrm{pH}$ ranges, the surface sorption sites were deprotonated leading to the increase of electrostatic interaction to take up Cs(I) with higher efficiency with a maximum adsorption between $\mathrm{pH} 7.5$ and 9.5. It is worth mentioning that the acidity of the medium decreased due to the release of $\mathrm{H}^{+}$ions as a result of the ion exchange of the surface protons by $\mathrm{Cs}(\mathrm{I})$ ions through the ion exchange mechanism.

3.2.2. Effect of equilibrium time. The time dependence of Cs(I) adsorption on the MMT-IEX was carried out mainly for two purposes; to reveal the applicability of MMT-IEX for the Cs(I) removal and to predict the adsorption mechanism. Adsorption of Cs(I) ions on MMT-IEX was studied within a time of $2 \mathrm{~h}$ at $25{ }^{\circ} \mathrm{C}$ and $\mathrm{pH} 9.5$ and the results obtained are shown in Fig. $4 \mathrm{~b}$. 
Within $15 \mathrm{~min}$, the uptake of Cs(I) represents $58.34 \%$ from the uptake capacity at the plateau. After that, the rate of $\operatorname{Cs}(\mathrm{I})$ adsorption slowed and reached the plateau region when the surface becomes saturated $\left(60.33 \mathrm{mg} \mathrm{g}^{-1}\right)$ within $90 \mathrm{~min}$ from a synthetic water sample containing $150 \mathrm{mg} \mathrm{L}^{-1}$ of cesium ions. The reason could be attributed to the porous structural features of MMT-IEX which facilitating the sorption of Cs(I) as well as surface hydrophilicity could be a factor responsible for surface active sites functional group interaction, which is entropically favorable. After $90 \mathrm{~min}$, the Cs(I) adsorption was decreased dramatically by increasing the time due to increasing of $\left[\mathrm{H}^{+}\right]$in a solution that drives the reaction to auto-desorption process.

The kinetic studies are of great importance for both gaining insights on the physical chemistry of the sorption processes and on the design of sorption systems. The relation between cesium adsorption and time was performed by several kinetic models to clarify the rate and mechanism of the adsorption reaction. Ho and McKay model (pseudo-second-order model) assumes that the sorption process could be a pseudo-chemical reaction process. In which, all adsorption steps including external/ internal diffusion and adsorption are lumped together. ${ }^{26}$

$$
t / q_{\mathrm{t}}=t / q_{2}+1 / k_{2} q_{2}^{2}
$$

Plotting of $t / q_{\mathrm{t}}$ versus $t$ (Fig. 4c) gave a straight line with a slope and an intercept, from which the $q_{2}$ (theoretical capacity) and $k_{2}$ (rate constant) were calculated. Clearly, a satisfactory harmonization was obtained between calculated and experimental values of $q_{\mathrm{e}}\left(68.49 \mathrm{mg} \mathrm{g}^{-1}\right)$ and gives higher correlation value $(0.97183)$ than that of the first order model, so the Cs(I) ions sorption rate on the MMT-IEX could be modeled with the second order model. In general, the sorption process is known to proceed through the following steps; bulk diffusion, film diffusion, pore diffusion and chemical reaction. The ratelimiting step results from one of the above steps or usually from the combination of them. For gaining insight into the sorption kinetic, the datasets time effect was used in the modeling computations and the obtained parameters are discussed in details. McKay model assumes that the adsorption process is controlled by the film- and particle diffusion. During the transport of the solute species from the bulk liquid phase towards the solid adsorbent surface, the boundary layer may play a significant role in the adsorption process. This may be verified by applying the adsorption time data to the liquid film diffusion model:

$$
\log (1-F)=-K_{\mathrm{F}} / 2.303 t
$$

where $K_{\mathrm{F}}$ is the film diffusion rate constant $\left(\mathrm{min}^{-1}\right)$ and $F$ equals the value of $q_{\mathrm{t}} / q_{\mathrm{e}}$. In case the plot of $\log (1-F)$ versus $t$ gives a straight line with intercept almost zero, this indicates that the adsorption may be controlled by the diffusion through the liquid film at the MMT-IEX interface (Fig. 4d). The rate constant for liquid film diffusion $\left(K_{\mathrm{F}}\right)$ was determined to be 0.028 . The non-zero intercept indicates that the film diffusion is not the rate-determining step in the studied adsorption process. The time dependence data of cesium adsorption by the mesoporous
MMT-IEX was modeled by Weber-Morris model to clearly know whether intra-particle diffusion or film diffusion is the ratelimiting step. ${ }^{27}$ This model state that the intraparticle diffusivity is constant and the direction of the diffusion process is radial;

$$
q_{\mathrm{e}}=X+K_{\mathrm{i}} t^{1 / 2}
$$

where $K_{\mathrm{i}}\left(\mathrm{mg} \mathrm{g}^{-1} \min ^{-0.5}\right)$ and $X$ are the intera-particle diffusion rate constant and constant proportional to the boundary layer thickness, respectively. The values of $K_{\mathrm{i}}$ and $X$ were determined from the slope and intercept of the plot $q_{\mathrm{t}} v s . t^{1 / 2}$ (Fig. 4e). Given the linear nature of the plot and the higher correlation value, the adsorption process is obviously controlled by an intraparticle diffusion mechanism. The small value of $X(0.09)$ indicates that the boundary layer thickness has a negligible effect on the adsorption process. Bangham model is also applicable to the adsorption systems in which the intraparticle diffusion is the rate-determining step. This model assumes that the diffusion of cesium into the mesopores of MMT-IEX nanoparticle is the rate-controlling step, the adsorption data were applied to Bangham model; ${ }^{28}$

$$
\log \left(C_{\mathrm{i}} / C_{\mathrm{i}}-A q_{\mathrm{t}}\right)=\log \log \left(A K_{\mathrm{B}} / 2.303 \mathrm{~V}\right)+B \log t
$$

where $B$ and $K_{\mathrm{B}}\left(\mathrm{mL} \mathrm{g}^{-1} \mathrm{~L}^{-1}\right)$ are Bangham constants and $A$ is the weight of MMT-IEX per liter of cesium solution $\left(\mathrm{g} \mathrm{L}^{-1}\right)$, the straight line with higher correlation value of Bangham model (Fig. 4f) confirms the probability of a pore diffusion controlled adsorption process. As a conclusion of the kinetic studies, it was clear that the Ho and McKay, Weber-Morris and Bangham models are better to describe the adsorption process of cesium ions by the MMT-IEX nanoparticles than the other studied models, and this was supported by the statistical indices obtained for each model.

3.2.3. Effect of $\mathrm{Cs}(\mathrm{I})$ ions concentration. Studying the effect of initial cesium ion concentration is important to understand and describe the mass transfer resistance of cesium ions between the aqueous and the MMT-IEX phases. The effect of $\mathrm{Cs}(\mathrm{I})$ ion concentrations on the adsorption process was investigated within the concentrations range from 0.5 to $150 \mathrm{mg} \mathrm{L}^{-1}$. The experimental conditions were set as follows: contact time of $90 \mathrm{~min}$ and an adsorbent dose of $1.5 \mathrm{~g} \mathrm{~L}^{-1}$. As clearly shown in Fig. 5a, the uptake of Cs(I) ions by MMT-IEX increases at low metal ion concentration till reaches a plateau at higher concentrations. This behavior is closely related to the concentration of surface active sites available for adsorption. At the beginning of adsorption many active sites would be available for interaction with $\mathrm{Cs}(\mathrm{I})$ ions and consequence the active sites become saturated and a dynamic equilibrium is achieved where the adsorption levels off at a maximum adsorption capacity of $60.33 \mathrm{mg} \mathrm{g}^{-1}$. A comparative study in terms of adsorption capacity has been carried out with other reported adsorbents, and the results are summarized in Table $1 .^{2,8,13,14,17,29-36}$ Cesium ions may be adsorbed from aqueous media onto the surface of MMT-IEX by several interaction modes. The effective mechanism is related to the nature of adsorption sites, surface 

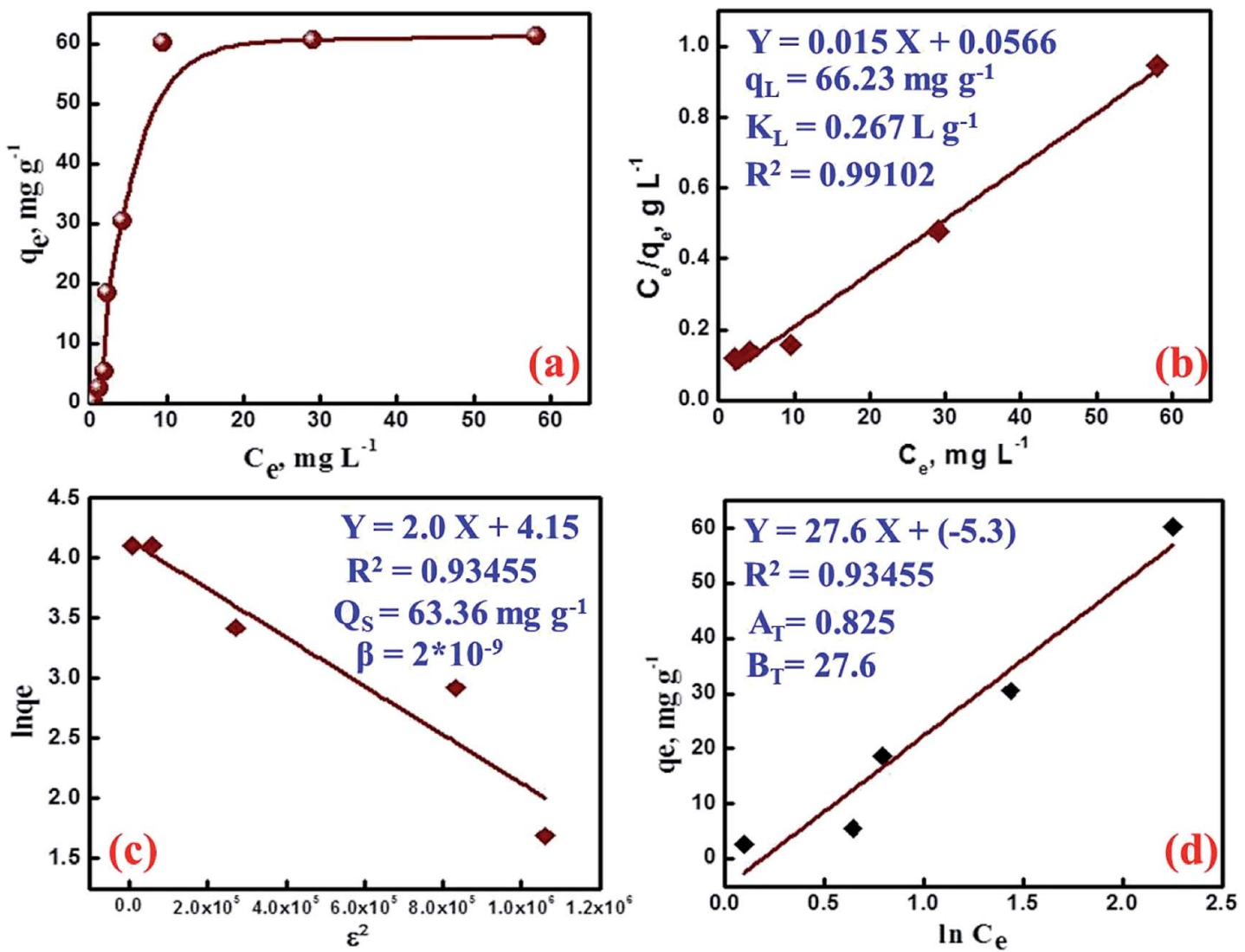

Fig. 5 (a) Isotherm of $\mathrm{Cs}($ I) ions adsorption on MMT-IEX from a single ion solution; $\mathrm{pH}$ 9.5, $30 \mathrm{mg}$ MMT-IEX weight, $20 \mathrm{~mL}$ solution volume, 20 min contact time and $25^{\circ} \mathrm{C}$. (b) Langmuir, (c) D-R, and (d) Temkin plots for the adsorption cesium on the MMT-IEX sorbent.

properties, affinities of the MMT-IEX adsorbent and the adsorption conditions. The experimental results were treated according to different adsorption models to verify the adsorption parameters that drive the adsorption process. Therefore, the experimental data of cesium adsorption onto mesoporous MMT-IEX were applied to the linear form of Langmuir isotherm: ${ }^{37}$

Table 1 Comparison of the adsorption capacities of Cs(I) ions onto various absorbents

\begin{tabular}{lcl}
\hline Adsorbent & Uptake, $\mathrm{mg} \mathrm{g}^{-1}$ & Ref. \\
\hline Silica/dibenzo-18-crown-6 ether & 27.40 & 2 \\
Silica/benzo-p-xylyl-22-crown-6-ether & 86.28 & 8 \\
MCM-41/zinc hexacyanoferrate & 103.09 & 13 \\
Silica/copper(II) ferrocyanide & 17.10 & 14 \\
Titanium oxide & 120.00 & 17 \\
$\mathrm{NH}_{4} \mathrm{HPA} / \mathrm{SBA}-15$ & 70.90 & 29 \\
Vermiculite/ethyl amine & 56.92 & 30 \\
$\mathrm{~K}_{2}[$ CoFe(CN) 6 ] & 141.44 & 31 \\
Iron ferrite & 155.00 & 32 \\
Polyaniline/titanotungstate & 217.00 & 33 \\
Silica/calix[4]arene-crown & 30.17 & 34 \\
Zirconium oxide & 40.00 & 35 \\
Hydroxyapatite & 69.49 & 36 \\
MMT-IEX & 60.33 & This work
\end{tabular}

$$
C_{\mathrm{e}} / q_{\mathrm{e}}=C_{\mathrm{e}} / q_{\mathrm{L}}+1 / K_{\mathrm{L}} q_{\mathrm{L}}
$$

where $K_{\mathrm{L}}\left(\mathrm{L} \mathrm{mg}^{-1}\right)$ and $q_{\mathrm{L}}\left(\mathrm{mg} \mathrm{g}^{-1}\right)$ are the Langmuir constant and the theoretical adsorption capacity calculated by plotting of $C_{\mathrm{e}} / q_{\mathrm{e}}$ against $C_{\mathrm{e}}$. Fig. $5 \mathrm{~b}$ shows a good straight line, with $R^{2}=$ 0.99102 , from which the values of $K_{\mathrm{L}}\left(0.267 \mathrm{~L} \mathrm{~g}^{-1}\right)$ and $q_{\mathrm{L}}$ (66.23 $\mathrm{mg} \mathrm{L}^{-1}$ ) were determined. The finding that the calculated values of $q_{\mathrm{L}}$ are comparable to that the experimental values indicate that the adsorption of $\mathrm{Cs}(\mathrm{I})$ ions on MMT-IEX is well fitted with Langmuir model. The value of $R_{\mathrm{L}},\left(R_{\mathrm{L}}=1 /\left(1+K_{\mathrm{L}} \times\right.\right.$ $\left.C_{\mathrm{i}}\right)$ ), gives an indication for the possibility of the adsorption process to proceed, $R_{\mathrm{L}}>1.0$ unsuitable; $R_{\mathrm{L}}=1$ linear; $0<R_{\mathrm{L}}<1$ suitable; $R_{\mathrm{L}}=0$ irreversible. The value of $R_{\mathrm{L}}$ was found to lie between 0.043 and 0.931 indicating the suitability of the MMTIEX as an adsorbent for the recovery of Cs(I) ions.

The Dubinin-Radushkevich (D-R) model was applied to estimate the energy of adsorption and nature of the adsorption process. The liner form of this model is more general than Langmuir model because it considers a heterogeneous surface. The linear form of the $\mathrm{D}-\mathrm{R}$ isotherm equations is as follow: ${ }^{38}$

$$
\ln \left(q_{\mathrm{e}}\right)=\ln q_{\mathrm{s}}-\beta\left(R T \ln \left(1+1 / C_{\mathrm{e}}\right)\right)^{2}=\ln q_{\mathrm{s}}-\beta \varepsilon^{2}
$$

where $q_{\mathrm{s}}$, and $E(E=1 / \sqrt{2 \beta})$ are the D-R adsorption capacity and the mean free energy, respectively. D-R plot shows 
a straight line from which the values of $\mathrm{D}-\mathrm{R}$ parameters were calculated (Fig. 5c). The obtained values of $E$ and $q_{\mathrm{s}}$ are $15.81 \mathrm{~kJ} \mathrm{~mol}^{-1}$ and $63.36 \mathrm{mg} \mathrm{g}^{-1}$, respectively. These values agree well with the experimental data indicating a chemical adsorption process. Moreover, the obtained $E$ values between 8 and $16 \mathrm{~kJ} \mathrm{~mol}^{-1}$ indicate cation ion-exchange and particle diffusion processes. Finally, Temkin adsorption isotherm considers that heat of adsorption of all active sites decreases linearly with increase coverage due to adsorbent-adsorbate interaction, and adsorption is characterized by a uniform distribution of the binding energies, up to certain maximum binding energy: ${ }^{28}$

$$
q_{\mathrm{e}}=B_{\mathrm{T}} \ln A_{\mathrm{T}}+B_{\mathrm{T}} \ln C_{\mathrm{e}}
$$

where $A_{\mathrm{T}}\left(\mathrm{L} \mathrm{g}^{-1}\right)$ and $B_{\mathrm{T}}\left(\mathrm{kJ} \mathrm{mol}^{-1}\right)$ are Temkin constants and the value of $B_{\mathrm{T}},\left(B_{\mathrm{T}}=R T / b_{\mathrm{T}}\right)$, is related to the adsorption energy constant $\left(b_{\mathrm{T}}\right) . A_{\mathrm{T}}$ and $B_{\mathrm{T}}$ values were calculated from the slope and intercept of Temkin plots (Fig. $5 \mathrm{~d}$ ). The estimated $B_{\mathrm{T}}$ values of MMT-IEX were found to be $27.614 \mathrm{~kJ} \mathrm{~mol}^{-1}$ (>40 kJ mol${ }^{-1}$ ), confirming that the adsorption process of Cs(I) on MTT-IEX proceed through ion exchange mechanism.

\section{Selectivity assessment}

The specificity of the fabricated MMT-IEX adsorbent was examined by evaluating its capability to selectively remove radioactive cesium ions, especially from its co-exist ions present in seawater and aquatic nuclear waste. The effect of competing species like $\mathrm{Li}(\mathrm{I}), \mathrm{Na}$ (I), $\mathrm{K}(\mathrm{I}), \mathrm{Mg}(\mathrm{II}), \mathrm{Ca}(\mathrm{II}), \mathrm{Sr}(\mathrm{II}), \mathrm{Ba}(\mathrm{II}), \mathrm{Rb}(\mathrm{I})$, $\mathrm{Fe}(\mathrm{III}), \mathrm{Al}(\mathrm{III}), \mathrm{Ni}$ (II), $\mathrm{Cu}$ (II), $\mathrm{Hg}$ (II), $\mathrm{Pb}$ (II), Mn(II), $\mathrm{Cd}(\mathrm{II}), \mathrm{La}$ (III), $\mathrm{Zr}$ (Iv), U(vI) and Th(Iv) on Cs(I) removal from aqueous solutions onto the mesoporous MMT-IEX was evaluated using three sequence cases at its optimal experimental conditions of $\mathrm{pH} 9$, MMT-IEX amount $40 \mathrm{mg}$, solution volume $30 \mathrm{~mL}$ at $25{ }^{\circ} \mathrm{C}$. Firstly, in binary solution, the interfering ions $\left(5 \mathrm{mg} \mathrm{L}^{-1}\right)$ were

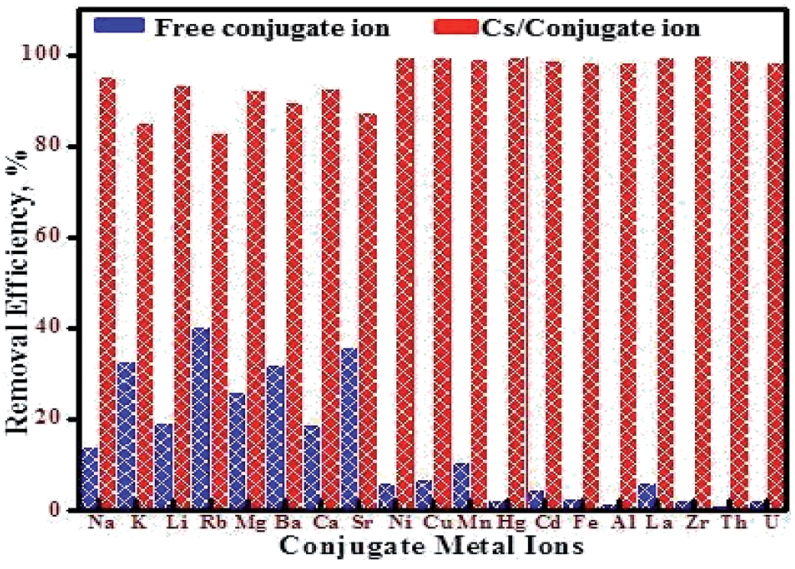

Fig. 6 Selectivity profiles of mesoporous MMT-IEX towards Cs(I) ions during the addition of various foreign metal ions $\left(5 \mathrm{mg} \mathrm{L}^{-1}\right)$ at optimal adsorption conditions (MMT-IEX weight $40 \mathrm{mg}$, volume solution 30 $\mathrm{mL}$, eq. time $90 \mathrm{~min}$ and $25^{\circ} \mathrm{C}$ ). The interfered cations listed in the

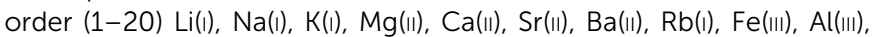

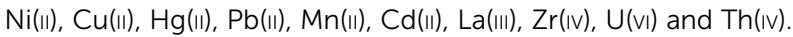

initially added to $1 \mathrm{mg} \mathrm{L^{-1 }}$ of $\mathrm{Cs}(\mathrm{I})$ ions. Result of selectivity studies from this binary system indicates that the metal ions such as $\mathrm{K}(\mathrm{I}), \mathrm{Rb}(\mathrm{I})$ and $\mathrm{Sr}(\mathrm{II})$ ions exerted a higher effect on the removal of Cs(I) ions than other ions (Fig. 6). Secondly, in the multi-mixture system, the effect of the interfering ions on Cs(I) removal was examined by carrying out the selectivity experiments in 4 groups of mixtures and each group contains 6 conjugated metal ions. The composition of each group of ions mixture includes, Group-I: $\mathrm{Cs}(\mathrm{I}), \mathrm{Li}(\mathrm{I}), \mathrm{K}(\mathrm{I}), \mathrm{Na}(\mathrm{I}), \mathrm{Rb}(\mathrm{I})$ and $\mathrm{Sr}(\mathrm{II})$, Group-II Cs(I), Mg(II), Ca(II), Ba(II), $\mathrm{Fe}($ III) and $\mathrm{Cd}(\mathrm{II})$, Group-III: $\mathrm{Cs}(\mathrm{I}), \mathrm{Al}(\mathrm{III}), \mathrm{Ni}$ (II), $\mathrm{Pb}$ (II), $\mathrm{Mn}$ (II) and $\mathrm{Hg}$ (II), Group-IV: $\mathrm{Cs}(\mathrm{I})$, $\mathrm{Cu}(\mathrm{II}), \mathrm{La}(\mathrm{III}), \mathrm{Zr}(\mathrm{IV}), \mathrm{U}(\mathrm{VI})$ and $\mathrm{Th}(\mathrm{IV})$. In this removal system the metal ions of Group-I displayed a greater impact on removal efficiency (\%) of Cs(I) ions than other groups (namely, hydrated ion size and relative charge density) at $\mathrm{pH}$ 9. Therefore, the removal efficiency of $\mathrm{Cs}(\mathrm{I})$ ions was increased gradually from Group-I to Group-IV; $88.4<93.1<95.5<98.6 \%$, respectively. Finally, the removal applicability of $\mathrm{Cs}(\mathrm{I})$ from simulated wastewater sample was carried out by initially adding $5 \mathrm{mg} \mathrm{\textrm {L } ^ { - 1 }}$ of $\mathrm{Li}(\mathrm{I}), \mathrm{Na}$ (I), K(I), $\mathrm{Mg}$ (II), $\mathrm{Ca}$ (II), $\mathrm{Sr}$ (II), $\mathrm{Ba}$ (II), $\mathrm{Rb}$ (I), $\mathrm{Fe}(\mathrm{III}), \mathrm{Al}(\mathrm{III})$, $\mathrm{Ni}(\mathrm{II}), \mathrm{Cu}$ (II), $\mathrm{Hg}$ (II), $\mathrm{Pb}$ (II), Mn(II), Cd(II), La(III), $\mathrm{Zr}$ (Iv), U(VI) and Th(Iv) ions to $1 \mathrm{mg} \mathrm{L}^{-1} \mathrm{Cs}(\mathrm{I})$ ion. The sample solution containing cesium ( $\mathrm{pH}$ 9) was studied according to the ion-selective procedure at optimal experimental conditions. Our findings that MMT-IEX achieves a high-performance recovery of $91.77 \%$ for Cs(I) ions. The selectivity of MMT-IEX can be ascribed to its high binding affinity for the interfering metal ions due to the intrinsic mobility of Cs(I) ions to bind MMT-IEX through ion exchange process derived from hydrated ion size and relative charge density (i.e. smaller the size of ion, the more highly is it hydrated). Greater the mass of a hydrated ion, the lower is its ionic mobility, which indicates that $\mathrm{K}(\mathrm{I})$ and $\mathrm{Rb}(\mathrm{I})$ can occupy a hydrated state more easily instead of adsorption on MMT-IEX because of its higher hydration energy. ${ }^{39}$ Moreover, the ICP-OES analysis of the collected $\mathrm{Cs}(\mathrm{I})$ ions solution indicates that approximately $99.3 \%$ of the $\operatorname{Cs}(\mathrm{I})$ metal ions were released using $0.05 \mathrm{M} \mathrm{HNO}_{3}$.

\section{Conclusions}

A nanostructured mesoporous calcium hydrogen phosphate (MMT-IEX) was fabricated through sol-gel method. The MMTIEX was characterized using FT-IR, XRD, SEM, TG, HRTEM, DLS and $\mathrm{N}_{2}$ adsorption/desorption techniques and the results confirmed the adsorbent formation as nanostructured mesoporous calcium phosphate. MMT-IEX was used as an effective sorbent for cesium ions from their aqueous solutions. The adsorption kinetic data was best modeled by Ho and McKay model. The adsorption isotherm data was best modeled by Langmuir, Temkin and $\mathrm{D}-\mathrm{R}$ isotherm. All the experimented data are discussed revealing the success of MMT-IEX as cation exchanger for the adsorption and separation of Cs from their media to a large extent. In summary, the fabricated monetite meso-sorbent achieves high-performance collection, recovery, and extraction of Cs(I) ions. Therefore, it is highly applicable to the environmental cleanup of radioactive cesium. 


\section{Conflicts of interest}

There are no conflicts to declare.

\section{References}

1 D. Alby, C. Charnay, M. Heran, B. Prelot and J. Zajac, Recent developments in nanostructured inorganic materials for sorption of cesium and strontium: Synthesis and shaping, sorption capacity, mechanisms, and selectivity-A review, $J$. Hazard. Mater., 2018, 344, 511-530.

2 M. R. Awual, S. Suzuki, T. Taguchi, H. Shiwaku, Y. Okamoto and T. Yaita, Selective cesium removal from radioactive liquid waste by crown ether immobilized new class conjugate adsorbent, Chem. Eng. J., 2014, 242, 127-135.

3 M. R. Awual, T. Yaita and T. Taguchi, Selective cesium removal from radioactive liquid waste by crown ether immobilized new class conjugate adsorbent, J. Hazard. Mater., 2014, 278, 8-18.

4 C. Vincent, A. Hertz, T. Vincent, Y. Barré and E. Guibal, Immobilization of inorganic ion-exchanger into biopolymer foams - Application to cesium sorption, Chem. Eng. J., 2014, 236, 202-211.

5 D. A. Lee, Solvent extraction of cesium and rubidium triphenylcyanoboron, J. Inorg. Nucl. Chem., 1972, 34, 28952901.

6 P. K. Mohapatra, D. S. Lakshmi, A. Bhattacharyya and V. K. Manchanda, Evaluation of polymer inclusion membranes containing crown ethers for selective cesium separation from nuclear waste solution, J. Hazard. Mater., 2009, 169, 472-479.

7 A. F. Tag El-Din, M. El-Khouly, E. A. Elshehy, A. A. Atia and W. A. El-Said, Microporous Mesoporous Mater., 2018, 265, 211-218.

8 M. R. Awual, T. Yaita, Y. Miyazaki, D. Matsumura, H. Shiwaku and T. Taguchi, A reliable hybrid adsorbent for efficient radioactive cesium accumulation from contaminated wastewater, Sci. Rep., 2016, 6, 19937.

9 M. R. Awual, Y. Miyazaki, T. Taguchi, H. Shiwaku and T. Yaita, Encapsulation of cesium from contaminated water with highly selective facial organic-inorganic mesoporous hybrid adsorbent, Chem. Eng. J., 2016, 291, 128-137.

10 M. R. Awual, Ring size dependent crown ether based mesoporous adsorbent for high cesium adsorption from wastewater, Chem. Eng. J., 2016, 303, 539-546.

11 C. B. Durrant, J. D. Begg, A. B. Kersting and M. Zavarin, Cesium sorption reversibility and kinetics on illite, montmorillonite, and kaolinite, Sci. Total Environ., 2018, 610-611, 511-520.

12 K.-Y. Lee, K.-W. Kim, M. Park, J. Kim, M. Oh, E.-H. Lee, D.-Y. Chung and J.-K. Moon, Novel application of nanozeolite for radioactive cesium removal from high-salt wastewater, Water Res., 2016, 95, 134e141.

13 S. Vashnia and H. Tavakoli, Zinc hexacyanoferrate loaded mesoporous MCM-41 as a new adsorbent for cesium: equilibrium, kinetic and thermodynamic studies, Desalin. Water Treat., 2015, 55, 1220-1228.

14 A. Takahashi, A. Kitajima, D. Parajuli, Y. Hakuta, H. Tanaka, S. I. Ohkoshi and T. Kawamoto, Radioactive cesium removal from ash washing solution with high $\mathrm{pH}$ and high $\mathrm{K}^{+}$concentration using potassium zinc hexacyanoferrate, Chem. Eng. Res. Des., 2016, 109, 513-518.

15 T. Sangvanich, V. Sukwarotwat and R. J. Wiacek, Selective capture of cesium and thallium from natural waters and simulated wastes with copper ferrocyanide functionalized mesoporous silica, J. Hazard. Mater., 2010, 182, 225-231.

16 Y. Gossuin, J.-M. Colet, A. Roch, R. N. Muller and P. Gillis, Cesium Adsorption in Hydrated Iron Oxide Particles Suspensions: An NMR Study, J. Magn. Reson., 2002, 157, 132-136.

17 E. H. Borai, M. M. Breky, M. S. Sayed and M. M. Abo-Aly, Synthesis, characterization and application of titanium oxide nanocomposites for removal of radioactive cesium, cobalt and europium ions, J. Colloid Interface Sci., 2015, 450, 17-25.

18 S. S. Kumar, M. V. Sivaiah, K. A. Venkatesan, R. M. Krishna, G. S. Murthy and P. Sasidhar, Removal of cesium and strontium from acid solution using a composite of zirconium molybdate and zirconium tungstate, $J$. Radioanal. Nucl. Chem., 2003, 258, 321-327.

19 V. N. Lebedev, N. A. Melnik and A. V. Rudenko, Sorption of Cesium on Titanium and Zirconium Phosphates, Radiochemistry, 2003, 45, 149-151.

20 J. Shen, M. F. Evangelista, G. Mkongo, H. Wen, R. Langford, G. Rosair, M. R. S. McCoustra and V. Arrighi, Efficient defluoridation of water by monetite nanorods, Adsorption, 2018, 24, 135-145.

21 M. M. Mirkovic, T. D. Lazarević Pasti, A. M. Dosen, M. Z. Cebela, A. A. Rosic, B. Z. Matovic and B. M. Babic, Adsorption of malathion on mesoporous monetite obtained by mechanochemical treatment of brushite, $R S C$ Adv. , 2016, 6, 12219-12225.

22 T. L. Yami, S. M. Butler and D. A. Sabatini, Preparation and Evaluation of Monetite as a High-Capacity Adsorbent for Fluoride Removal from Drinking Water, J. Environ. Eng., 2018, 144, 04017081.

23 M. H. Prado Da Silva, J. H. C. Lima, G. A. Soares, C. N. Elias, M. C. de Andrade, S. M. Best and I. R. Gibson, Transformation of monetite to hydroxyapatite in bioactive coatings on titanium, Surf. Coat. Technol., 2001, 137, 270276.

24 J. Duncan, J. F. MacDonald, J. V. Hanna, Y. Shirosaki, S. Hayakawa, A. Osaka, J. M. S. Skakle and I. R. Gibson, The role of the chemical composition of monetite on the synthesis and properties of $\alpha$-tricalcium phosphate, Mater. Sci. Eng., C, 2014, 34, 123-129.

25 L. Tortet, J. R. Gavarri and G. Nihoul, Study of protonic mobility in $\mathrm{CaHPO}_{4} \cdot 2 \mathrm{H}_{2} \mathrm{O}$ (Brushite) and $\mathrm{CaHPO}_{4}$ (Monetite) by infrared spectroscopy and neutron scattering, J. Solid State Chem., 1997, 132, 6-16.

26 Y. S. Ho and G. McKay, Pseudo-second order model for sorption processes, Process Biochem., 1999, 34, 451-465. 
27 W. J. Weber, J. C. Morris and J. Sanit, Kinetics of adsorption on carbon from solution, J. Sanit. Eng. Div., 1963, 89, 31-59.

28 M. O. Abd El-Magied, E. A. Elshehy, E. A. Manaa, A. A. Tolba and A. A. Atia, Kinetics and thermodynamics studies on the recovery of thorium ions using amino resins with magnetic properties, Ind. Eng. Chem. Res., 2016, 55, 11338-11345.

29 Y. Park and W. S. Shin, Ammonium salt of heteropoly acid immobilized on mesoporous silica (SBA-15): An efficient ion exchanger for cesium ion, Chem. Eng. J., 2013, 220, 204-213.

30 H. Long, P. Wu, L. Yang and Z. Huang, Efficient removal of cesium from aqueous solution with vermiculite of enhanced adsorption property through surface modification by ethylamine, J. Colloid Interface Sci., 2014, 428, 295-301.

31 L. Zhao, J. Dudek, H. Polkowska-Motrenko and A. J. Chmielewski, A magnetic nanosorbent for cesium removal in aqueous solutions, Radiochim. Acta, 2016, 104, 423-433.

32 R. R. Sheha and E. Metwally, Equilibrium isotherm modeling of cesium adsorption onto magnetic materials, $J$. Hazard. Mater., 2007, 143, 354-361.
33 I. M. El- Naggar, E. S. Zakaria and I. M. Ali, Removal of cesium on polyaniline titanotungstate as composite ion exchanger, Adv. Chem. Eng. Sci., 2012, 2, 166-179.

34 A. Zhang and Z. Chai, Adsorption property of cesium onto modified macroporous silicacalix[4]arene-crown based supramolecular recognition materials, Ind. Eng. Chem. Res., 2012, 51, 6196-6204.

35 K. Qin, F. Li, S. Xu, T. H. Wang and C. H. Liu, Sequential removal of phosphate and cesium by using zirconium oxide: A demonstration of designing sustainable adsorbents for green water treatment, Chem. Eng. J., 2017, 322, 275-280.

36 S. S. Metwally, I. M. Ahmed and H. E. Rizk, Modification of hydroxyapatite for removal of cesium and strontium ions from aqueous solution, J. Alloys Compd., 2017, 709, 438-444.

37 I. Langmuir, The adsorption of gases on plane surfaces of glass, mica and platinum, J. Am. Chem. Soc., 1918, 40, 1361-1403.

38 M. M. Dubinin and L. V. Radushkevich, Evaluation of microporous materials with a new isotherm, Dokl. Akad. Nauk SSSR, 1947, 55, 327-329.

39 J. Lee, S.-M. Park, E.-K. Jeon and K. Baek, Selective and irreversible adsorption mechanism of cesium on illite, Appl. Geochem., 2017, 85, 188-193. 